\title{
Tipo de nefrectomía en el donante
}

\author{
Donor nephrectomy types \\ Francisco T Rodríguez-Covarrubias* \\ * Cirujano Urólogo. Departamento de Urología del Instituto Nacional de Ciencias Médicas y Nutrición Salvador Zubirán
}

\section{¿CUÁL TÉCNICA Y PARA QUIÉN?}

\section{Generalidades}

Como lo recalcan las Guías de Trasplante de Donador Vivo de la Sociedad Británica de Trasplantes, ${ }^{1}$ la cirugía de donador vivo es una subespecialidad única en el ámbito de la cirugía, razón por la cual se sugiere llevarla a cabo con los más altos estándares de calidad, por cirujanos entrenados y con amplia experiencia, y tras una evaluación clínica meticulosa del candidato a donador. Estos pacientes son seleccionados por su buen estado de salud y no por tener un padecimiento; por lo tanto, la donación -más allá de los potenciales beneficios psicológicos por realizar un acto altruistasólo podría acarrear el riesgo de daño. Esto se traduce en una gran responsabilidad para todo el equipo de trasplantes (cirujanos, urólogos, nefrólogos, enfermería, etcétera) que implica dar la mejor atención para reducir la posibilidad de complicaciones.

Existe evidencia sólida a favor de la nefrectomía laparoscópica de donador (NLD), incluyendo revisiones sistemáticas y metaanálisis que la comparan con la cirugía abierta. ${ }^{2}$ La NLD tiene resultados similares a los de la cirugía abierta en cuanto a función del injerto, complicaciones y supervivencia de los pacientes y del injerto, pero con menor requerimiento de analgésico, menor estancia hospitalaria y un retorno más pronto a las actividades cotidianas.

\section{Ventajas a favor de la nefrectomía abierta}

- Menor tiempo quirúrgico y menor tiempo de isquemia caliente.
Ventajas a favor de la nefrectomía laparoscópica ${ }^{3}$

- Menor sangrado, estancia hospitalaria, regreso al trabajo.

- Similar tasa de complicaciones, mejor calidad de vida.

- Función retardada del injerto similar.

- Función renal del receptor similar a un año después del trasplante.

Para determinar el lado del riñón a «procurar» se debe considerar el tamaño de ambos riñones del donador. Se sugiere tomar el riñón que sea más pequeño (más de $10 \%$ de diferencia en tamaño), que aporte menos del $45 \%$ de la función renal dividida o que tenga menor número de vasos sanguíneos (arterias, ramas arteriales, venas). Si la diferencia de tamaño o de función es mínima y no se encuentran variantes anatómicas vasculares, se prefiere tomar el riñón izquierdo, ya que tiene vasos de mayor longitud, lo que podría facilitar la cirugía. ${ }^{4}$

Las guías de KDIGO Living Donor Work Group ${ }^{5}$ sugieren que el cirujano que realizará la nefrectomía de donador tenga entrenamiento y experiencia adecuados para llevarla a cabo. Sugieren también que el abordaje óptimo propuesto al donador para la procuración renal sea la cirugía laparoscópica o la cirugía laparoscópica asistida con la mano, salvo en aquellos casos de cirugías previas extensas, adherencias o en centros sin experiencia en laparoscopia, en los que la cirugía abierta podría ser una opción aceptable. ${ }^{5}$

La donación renal proveniente de donadores vivos es segura, con una tasa baja de complicaciones a corto pla- 
zo. ${ }^{6}$ Con el protocolo de recuperación mejorada después de cirugía (ERAS, Enhanced Recovery After Surgery) es posible mantener los resultados y ventajas ya conocidas de la cirugía laparoscópica en los donadores renales. ${ }^{7}$

Se debe informar al donador vivo sobre la importancia de un estilo de vida saludable y un seguimiento permanente para identificar factores de riesgo modificables, que permitan que su estado de salud se mantenga en condiciones óptimas a mediano y largo plazo.

\section{REFERENCIAS}

1. BTS LDKT Guidelines Guidelines for living donor kidney transplantation. 4th edition. December 2017. Disponible en: https://bts.org.uk/wp-content/uploads/2018/01/BTS_LDKT_UK_ Guidelines_2018_Consultation_Draft.pdf.

2. Wilson $\mathrm{CH}$, Sanni A, Rix DA, Soomro NA. Laparoscopic versus open nephrectomy for live kidney donors. Cochrane Database Syst Rev. 2011; (11): CD006124.

3. Yuan H, Liu L, Zheng S, Yang L, Pu C, Wei Q et al. The safety and efficacy of laparoscopic donor nephrectomy for renal transplantation: an updated meta-analysis. Transplant Proc. 2013; 45: 65-76.

4. Knight SR, Cao KN, South M, Hayward N, Hunter JP, Fox J. Development of a clinical decision support system for living kidney donor assessment based on national guidelines. Transplantation. 2018; 102 (10): e447-e453.

5. Lentine KL, Kasiske BL, Levey AS, Adams PL, Alberú J, Bakr $\mathrm{MA}$ et al. KDIGO clinical practice guideline on the evaluation and care of living kidney donors. Transplantation. 2017; 101 (8S Suppl 1): S1-S109.

6. Villeda-Sandoval $\mathrm{Cl}$, Rodríguez-Covarrubias $\mathrm{F}$, Cortés-Aguilar G, Alberú-Gómez J, Vilatobá-Chapa M, Sotomayor M et al. Hand-assisted laparoscopic versus open donor nephrectomy: a retrospective comparison of perioperative and functional results in a tertiary care center in Mexico. Transplant Proc. 2013; 45 (9): 3220-3224.

7. Cowan NG, Kuhr CS. The benefit of an enhanced recovery program for living kidney donors. Eur Urol Focus. 2018; 4 (2): 146-147.

Correspondencia:

Dr. Francisco T Rodríguez-Covarrubias E-mail: francisco.rodriguezc@incmnsz.mx 